\title{
The clinicopathological significance of Bax and Bcl-2 protein expression with tumor infiltrating lymphocytes in ovarian carcinoma
}

\author{
S. YIGIT' ${ }^{1, *}$, L. DEMIR ${ }^{2}$, M. O. TARHAN ${ }^{2}$, F. K. CABUK ${ }^{3}$, H. ELLIDOKUZ ${ }^{4}$, C. ERTEN ${ }^{2}$, I. SOMALI ${ }^{2}$, A. DIRICAN ${ }^{2}$, F. CAKALAGAOGLU ${ }^{1}$
}

${ }^{1}$ Izmir Ataturk Training and Research Hospital, Department of Pathology; ${ }^{2}$ Izmir Ataturk Training and Research Hospital, Department of Medical Oncology; ${ }^{3}$ Aliaga State Hospital Department of Pathology; ${ }^{4}$ Dokuz Eylul University, Faculty of Medicine, Institute of Oncology, Department of Preventive Oncology

*Correspondence: seyranyigit@hotmail.com

Received January 27, 2012 / Accepted March 12, 2012

\begin{abstract}
The aim of the study was to establish the prognostic and predictive value of Bax and Bcl-2 proteins in conjunction with the host immune response in primary epithelial ovarian carcinoma.

83 patients were evaluated. Immunohistochemical staining was performed using anti-Bcl-2 (Dako; clone 124) and antiBax (Springbio; E17994) monoclonal antibodies. Additionally, the number of lymphocytes within tumor stroma lymphocyte nests were counted.

Bcl-2 protein expression was lower in advanced stage than early stage $(\mathrm{p}=0.005)$. High $(\mathrm{H})$ Bax expression was associated with longer overall survival (OS) than lower (L) Bax expression ( $\mathrm{p}=0.03)$. The OS of the (L) Bax/(L) Bcl-2 group was shorter than $(\mathrm{H}) \mathrm{Bax} /(\mathrm{L}) \mathrm{Bcl}-2$ group in advanced stage $(\mathrm{p}=0.05)$. The platinum-sensitive group had a statistically significant tendency for high Bax expression ( $\mathrm{p}=0.04)$. Furthermore, the intensity of the lymphocyte infiltration was associated with tumor differentiation $(\mathrm{p}=0.003)$.

Our data suggests that $(\mathrm{H})$ Bax protein expression prolongs survival, predicts platinum sensitivity and can be used after confirmation of this hypothesis in further prospective studies. The combined evaluation of Bax and Bcl-2 protein expression may provide additional significant prognostic information. The quantity of lymphocyte infiltration could be important for prognostic outcome.
\end{abstract}

Key words: Bax, Bcl-2, ovarian cancer, platinum sensitivity, lymphocyte infiltrate

Epithelial ovarian cancer is the most common cause of death among women with gynecologic cancer and the fifth leading cause of cancer deaths in all women [1]. In ovarian cancer, the prognostic factors can be divided into three groups: patient factors, tumor factors and treatment factors. Age and performance status are important patient factors that significantly influence the survival rate. Tumor factors such as the stage, histopathological findings, histologic grade and expression of cancer-related genes, also significantly affect survival. The residual tumor size, post-operative CA 125 level and the chemotherapeutic regimen, are important treatment factors for prognosis [2].

The Bcl-2 family is a growing family of genes, which plays a major role in the regulation of cell suicide, acting either as inhibitors (e.g., Bcl-2, bcl-xl, mcl-1) or promoters (e.g., Bclxs, Bax, bak, bad) of apoptosis [3]. Expression of Bcl-2, the major inhibitor of apoptosis, is connected with parameters of favorable prognosis and prolonged survival in breast cancer; however in ovarian cancer the results are conflicting $[4,5]$. The $\mathrm{Bcl}-2$ interacting protein, $\mathrm{Bax}$, is a proapoptotic member of Bcl-2 family and is the main antagonist of Bcl-2. Bax expression, in contrast to $\mathrm{Bcl}-2$ expression, was associated with an unfavorable outcome as well as with negative histopathological features [6]. Tumor-infiltrating lymphocytes (TILs) occur as a host response to several types of human carcinomas [7]. Several studies have evaluated the impact of T-lymphocyte infiltration on prognosis in ovarian cancer [8-13]. The presence of TILs (especially CD8+ subtype) appear to confer a survival advantage in some of these studies $[8,11-13]$. The aim of presented study was to investigate the effects of Bax and $\mathrm{Bcl}-2$ protein expression and the presence of TILs on survival and response to chemotherapy and to determine their correlation with clinicopathological features in primary epithelial ovarian carcinoma. 


\section{Materials and methods}

Patients and tumors. The current study was performed on archival materials of 83 patients who were diagnosed with epithelial ovarian carcinoma by the Department of Pathology and treated in the Clinic of Medical Oncology, Izmir Ataturk Training and Research Hospital from 2003-2008. Primary standard ovarian carcinoma surgery was performed by three different departments of Gynecology and Obstetrics in the same hospital. A suboptimal cytoreduction was defined as when residual disease was greater than $>1 \mathrm{~cm}$. Disease staging was performed using the criteria of the International Federation of Gynecology and Obstetrics (FIGO). Histologic typing and grading were assessed on paraffin-embedded tissue specimens according to the classification of the World Health Organization (WHO) [14]. The median age of the patients was $54 \pm 10.5$ years (range $32-80$ ). Patients received standard platinum-based combination chemotherapy regimens [Carboplatin plus Paclitaxel (Carboplatin AUC-6, Paclitaxel $175 \mathrm{mg} / \mathrm{m}^{2}$ );

Table 1 Patient and tumour characteristics

\begin{tabular}{lc}
\hline Patients characteristics & Whole group \\
\hline Age & \\
Range & $32-80$ \\
Median & $54 \pm 10.5$ \\
Histological type & \\
Serous & $50(60.2 \%)$ \\
Endometrioid & $15(18.2 \%)$ \\
Mixed & $8(9.6 \%)$ \\
Mucinous & $5(6 \%)$ \\
Clear cell & $3(3.6 \%)$ \\
Undifferantiated & $2(2.4 \%)$ \\
Histological grade & \\
Well differantiated & $13(15.7 \%)$ \\
Moderately differantiated & $32(38.6 \%)$ \\
Poorly differantiated & $38(45.8 \%)$ \\
FIGO stage & \\
Early stage & $38(45.7 \%)$ \\
Advanced stage & $45(54.2 \%)$ \\
Residual tumor & \\
$<1$ cm & $43(51.8 \%)$ \\
$>1$ cm & $39(46.9 \%)$ \\
Unknown & $1(1.2 \%)$ \\
Response to chemotherapy & \\
Complete & $66(79.5 \%)$ \\
Partial & $6(7.2 \%)$ \\
Ptable disease & $4(4.8 \%)$ \\
Unknown & $6(7.2 \%)$ \\
Platinium sensivitiy & $1(1.2 \%)$ \\
Hensitive & \\
Resistant & $20(24.2 \%)$ \\
\hline & $27(32.5 \%)$ \\
& $36(43.3 \%)$ \\
\hline
\end{tabular}

Cisplatin plus Docetaxel (Cisplatin $75 \mathrm{mg} / \mathrm{m}^{2}$, Docetaxel 75 $\mathrm{mg} / \mathrm{m}^{2}$ ) ; CAP ( Cisplatin $50 \mathrm{mg} / \mathrm{m}^{2}$, Doxorubicine $50 \mathrm{mg} / \mathrm{m}^{2}$, Cyclophosphamide $500 \mathrm{mg} / \mathrm{m}^{2}$ )] in each three-week cycle for for minimum six cycles. The majority of patients had received second-line chemotherapy $(n=43,51.8 \%)$. Ten patients received chemotherapy regimen through the fourth-line, while one patient received through the sixth-line and one received seventh-line during the follow-up time.

The follow-up time was defined as the time from diagnosis (operation or debulking procedure) to death or last visit, whichever came first. The median follow-up time was $32.3 \pm 13.8$ months (range 8-76 months). The mean postoperative CA125 level was $138 \mathrm{U}$-L in early stage cases, while it was $415 \mathrm{U}$-L in advanced disease cases. A detailed description of the patient and tumor characteristics is listed in Table 1 .

Immunohistochemistry. Immunohistochemical staining was performed on formalin-fixed and paraffin-embedded tissue using the streptavidin-biotin complex method. We applied non-immune blocking protein solution $(\mathrm{DAKO} \times 0909$, Carpentaria, CA VSP) $(1 \times 5 \mathrm{~min})$ at room temperature. Tissue sections were then incubated with primary antibodies, anti Bcl-2 (Dako clone 124) and Bax (1.200 spring B10 E 17994), for $2 \mathrm{~h}$ at room temperature. Diaminobenzidine (DAB) was used as a chromogen for reaction visualization. Finally, the sections were counterstained with Mayer's hematoxylin, dehydrated, cleared with xylene and mounted with coverslips using a permanent mounting medium.

Staining Analysis. All sections were examined with light microscopy independently by two observers (SY and FKC). Tonsil tissue and normal breast tissue were used as positive controls for Bcl-2 and Bax staining, respectively. When possible, depending on the amount of tumor tissue available, 300 epithelial tumor cells were counted, and the results are expressed as the percentage of positive tumor cells. The immunostaining was evaluated on a scale of $0-3$ points according to the percentage of cytoplasmic cancerous cells that stained positively; $<5 \%$ of carcinoma cell staining was termed negative, 6-25\% positivity was termed 1 point, $26-50 \%$ positivity was termed 2 points, and $>50 \%$ positivity was termed 3 points. According to the staining intensity, the immunostaining was evaluated on a scale of 1-3 points (1 point: weakly, 2 points: moderately, 3 points: strongly positive). Points for the intensity staining (IS) and percentage $(\% \mathrm{~S})$ of positive cells were added together, and an overall score (os 0-3) was assigned. Tumors were categorized into four groups based on the os as follows: 1 - Negative expression ( 0 or $<5 \%$ cells stained regardless of intensity); 2 -Weak expression 1 (os,1) 1 to 2 points; 3 - Moderate expression (os, 2) 3 to 4 points; 4 - Strong expression (os, 3 ) 5 to 6 points. For statistical analysis, the patients were dichotomized into two groups: low (L) expression (os, 0 or 1 ), including those with negative or weak expression, and high $(\mathrm{H})$ expression (os, 2 or 3), including those with moderate or strong expression (Figure 1-2). 


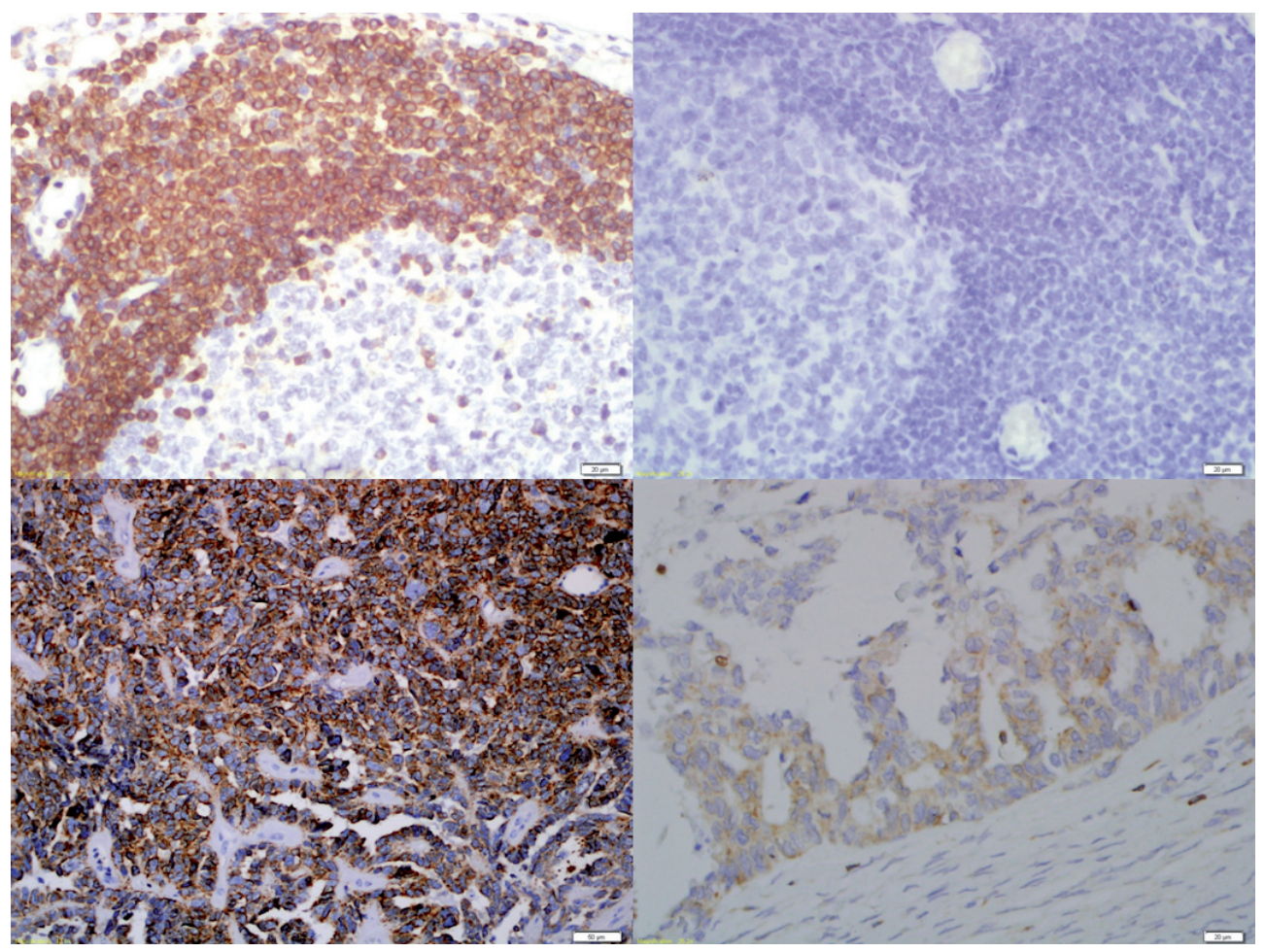

Figure 1. Immunohistochemical staining of Bcl-2 positive control (upper left) and negative control (upper right) in the tonsil tissue and high Bcl-2 (lower left) and low Bcl-2 expression (lower right) in the serous ovarian carcinoma (x 44).

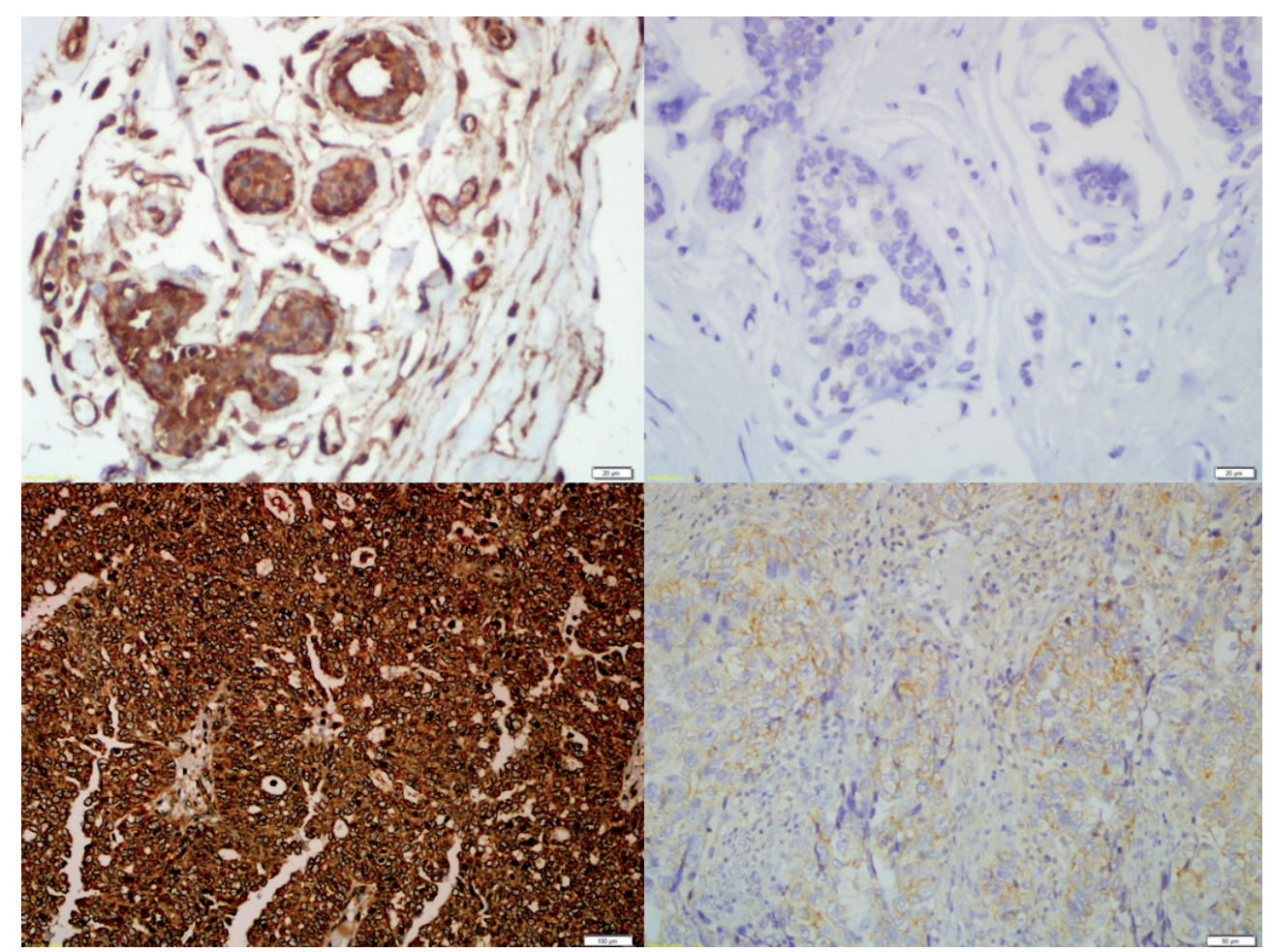

Figure 2. Immunohistochemical staining of Bax positive control (upper left) and negative control (upper right) in the breast tissue and high Bax (lower left) and low Bax expression (lower right) in the serous ovarian carcinoma (x44). 


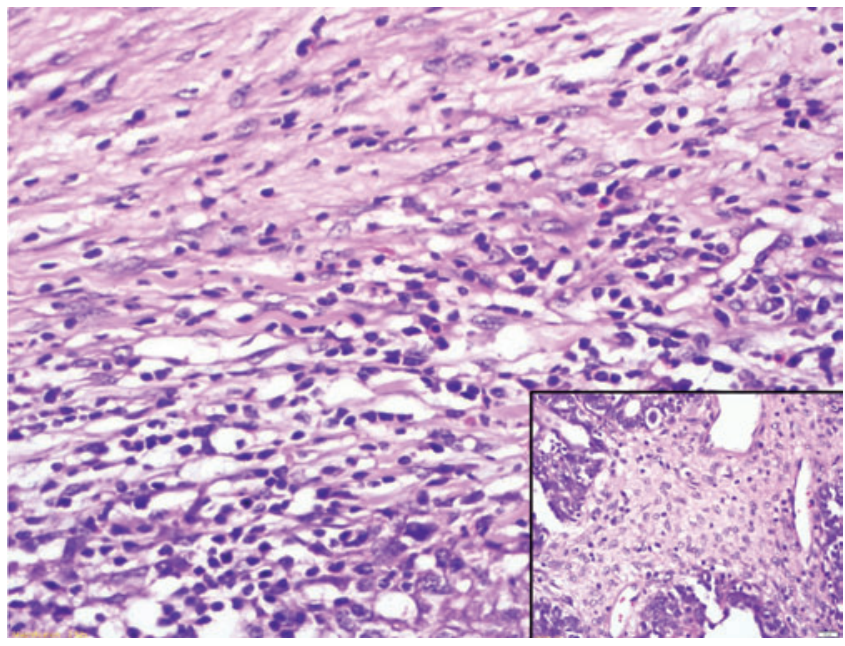

Figure 3. Tumor infiltrating lymphocytes in a high presence group in the serous carcinoma. (Inset: Tumor infiltrating lymphocytes in a low presence group) ( $x 44)$

Evaluation of tumor infiltrating lymphocytes (TILs). The presence of lymphocyte nests in each section was observed and evaluated by counting the number of groups of ten or more lymphocytes in 10 random viewings under a microscope at $100 x$. The number of lymphocytes in each nest was also counted and grouped into 5 categories: < 25, 25-50, 50-75, $75-100$, and $>100$ lymphocytes per nest. TIL number was classified as low, $(\mathrm{L})<25$ per nest, or high, $(\mathrm{H}) \geq 25$ per nest for statistical analysis (Figure 3).
Evaluation of clinical response to chemotherapy. The response to chemotherapy was evaluated according to the WHO response criteria [15]. Complete remission (CR) was defined as the normalization of CA125 levels in patients who had a higher level at baseline and the disappearance of findings in computerized tomography after first-line chemotherapy and confirmation at four weeks. Disease-free survival (DFS) was used for early stage individuals (stage I-II) who usually had surgery for optimal cytoreduction, while progression-free survival (PFS) was used for advanced disease individuals (stage III-IV). Disease (or progression)free survival is defined as the time from the diagnosis until relapse (or progression) or death (from any cause) or last visit, whichever occurs first. Overall survival (OS) was defined as the time from diagnosis to the last visit or death. The patients with CR were also classified as platinum sensitive (DFS or PFS longer than six months) and platinum highly sensitive (DFS or PFS longer than 24 months). The other responses were defined as partial, stabile and progressive disease, which were also described as the platinum-resistant group (Table 1).

Statistical Analysis. All of the calculations were performed using the SPSS 17 (Statistical Package for the Social Sciences, version 17) statistical program. Descriptive analysis was used to define the means and medians of numerical values. The associations between age, grade, histological type, stage, lymphocyte infiltrates and expression of Bax and Bcl-2 were performed using the chi-square test. All tests were two sided and the level of significance was set at $5 \%$. The probability of DFS, PFS and OS was estimated using a Kaplan-Meier analysis. Survival analysis was also

Table 2. The distrubition of $\mathrm{Bax}, \mathrm{Bcl}-2$ proteins according to clinicopathological features.

\begin{tabular}{|c|c|c|c|c|c|c|}
\hline & L-Bax & H-Bax & $P$ value & L-Bcl-2 & $\mathrm{H}-\mathrm{Bcl}-2$ & $P$ value \\
\hline \multicolumn{7}{|l|}{ Age group } \\
\hline$\leq 50$ years & $11(33.3 \%)$ & $22(66.7 \%)$ & 0.81 & 27 (81.8\%) & $6(18.2 \%)$ & 0.78 \\
\hline$>50$ years & $18(36 \%)$ & $32(64 \%)$ & & $39(78 \%)$ & $11(22 \%)$ & \\
\hline \multicolumn{7}{|l|}{ Histologic type } \\
\hline Serous & $20(40 \%)$ & $30(60 \%)$ & & $39(78 \%)$ & $11(22 \%)$ & \\
\hline Endometrioid & $4(26.6 \%)$ & $11(73.3 \%)$ & & $10(66 \%)$ & $5(33 \%)$ & \\
\hline Mixed & $5(62.5 \%)$ & $3(37.5 \%)$ & 0.44 & $8(100 \%)$ & $0(0 \%)$ & 0.91 \\
\hline Mucinous & $0(0 \%)$ & $5(100 \%)$ & & $5(100 \%)$ & $0(0 \%)$ & \\
\hline Clear cell & $0(0 \%)$ & $3(100 \%)$ & & $3(100 \%)$ & $0(0 \%)$ & \\
\hline Undifferantiated & $0(0 \%)$ & $2(100 \%)$ & & $1(50 \%)$ & $1(50 \%)$ & \\
\hline \multicolumn{7}{|l|}{ Histologic grade } \\
\hline Well differantiated & $4(30.7 \%)$ & $9(69.2 \%)$ & & $10(76.9 \%)$ & $3(23 \%)$ & \\
\hline Moderately differentiated & $14(33-3 \%)$ & $18(42.8 \%)$ & 0.06 & $27(64.2 \%)$ & $5(11.9 \%)$ & 0.89 \\
\hline Poorly differentiated & $11(28.9 \%)$ & $27(71.8 \%)$ & & $29(76.3 \%)$ & $9(23 \%)$ & \\
\hline \multicolumn{7}{|l|}{ FIGO stage } \\
\hline Early stage (I-II) & $11(28.9 \%)$ & $27(71.0 \%)$ & & $25(65.7 \%)$ & $13(34.2 \%)$ & \\
\hline Advanced stage (III-IV) & $18(40 \%)$ & $27(60 \%)$ & 0.44 & $41(91.2 \%)$ & $4(8.8 \%)$ & 0.005 \\
\hline \multicolumn{7}{|l|}{ Residual Disease } \\
\hline$<1 \mathrm{~cm}$ & $14(32.5 \%)$ & $29(67.4 \%)$ & & $31(72 \%)$ & $12(27.9 \%)$ & \\
\hline$>1 \mathrm{~cm}$ & $15(38.4 \%)$ & $24(61.5 \%)$ & 0.93 & $34(87.1 \%)$ & $5(12.8 \%)$ & 0.37 \\
\hline
\end{tabular}




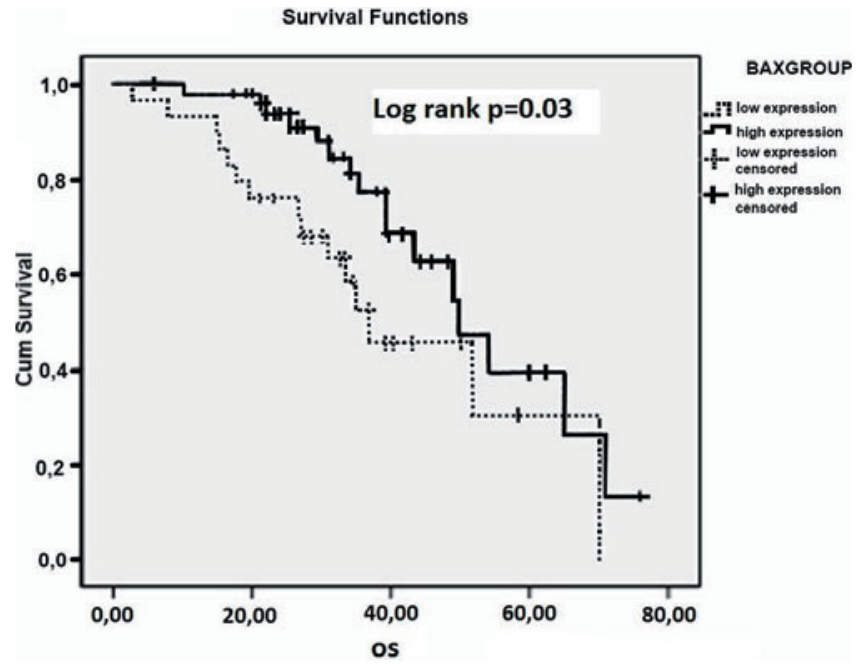

Figure 4. Overall survival comparison according to the Bax protein expression in the entire patient population.

performed according to stratified subgroups (1.Bax, 2.Bcl2, 3.Bax-Bcl-2 couplet, 4. Tumor infiltrating lymphocytes (TILs), 5.TIL combined with Bax and Bcl-2 expression together). The survival analysis comparison within groups were performed by using Log-rank test; $p$ value $<0.05$ was defined as significant. Correlation analysis between two variables was investigated by using Kendall correlation test. Univariate and multivariate analysis of Cox regression were used to explore the independent significance of the variables on survival. No formal sample size calculation was performed due to the explorative nature of the study.

\section{Results}

Overall positive expression of Bcl-2 was found in 24 of 83 cases $(28.9 \%)$, while overall positive expression of Bax was found in 58 of 83 cases $(69.8 \%)$. The patients were dichotomized into two groups, low expression and high expression, as described in the materials and methods section (Table 2)

Protein expression according to patient group and tumor characteristics. The expression of Bax and $\mathrm{Bcl}-2$ protein was also evaluated in two age groups; statistically, there was no significant expression difference for both $(\mathrm{p}=0.81$ for $\mathrm{Bax}$ and $\mathrm{p}=0.78$ for $\mathrm{Bcl}-2$ ) (Table 2).No significant association was found between histological type-tumor differentiation and Bax-Bcl-2 expression (Table 2). There was no difference between Bax expression in early and advanced disease $(p=0.44)$ however, Bcl-2 expression level was significantly lower in advanced disease when compared with early disease $(p=0.005)$ (Table 2). In addition, we could not find an association between these protein expression levels and postoperative serum CA125 levels $(\mathrm{p}=0.5)$ and/or age $(\mathrm{p}=0.4)$. No correlation was found between $\mathrm{Bax}$ and $\mathrm{Bcl}-2$ protein expression in univariate analysis ( $\mathrm{p}=0.056$; Kendall tau $\mathrm{r}=0.18)$.

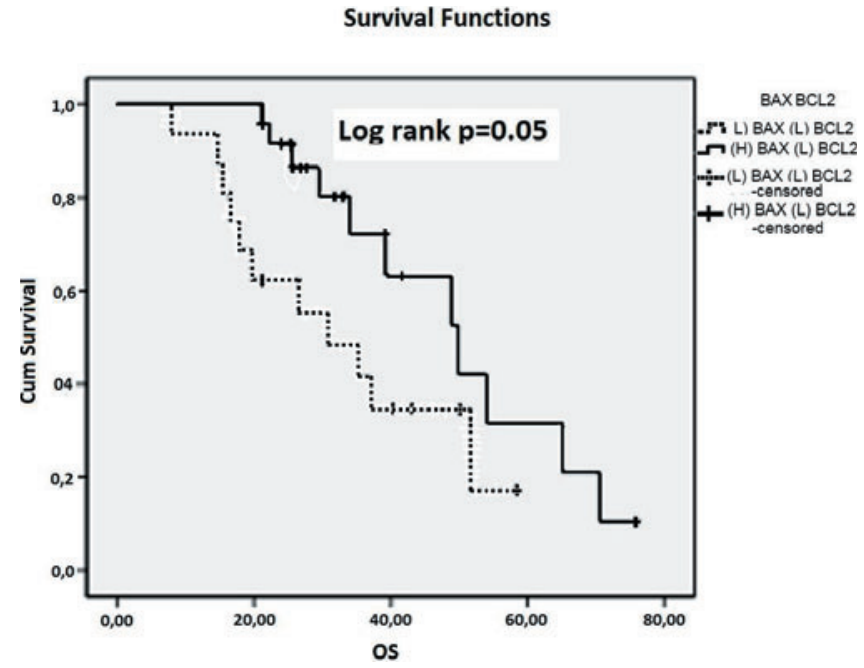

Figure 5. Overall survival comparison of low Bax/low Bcl-2 expression and high Bax/low Bcl-2 expression groups in advanced stages.

Survival significance of protein expression. The estimated median overall survival (OS) at a median 32.3 months follow-up time was 47.8 months (40.3-57.1 months $95 \%$ CI) for the entire study group. OS was significantly higher in early stages (59.3 months) as compared with advanced stages (37.8 months). Thirty-one patients (37. 3\%) died due to ovarian cancer. The longest survival prior to death was 70.5 months after diagnosis, while the shortest was 7.9 months after diagnosis.

Entire patient population. Patients with $(\mathrm{H})$ Bax expression had longer OS than patients with (L) Bax expression (49.8 vs. 36.9 months; $\mathrm{p}=0.03$ ) (Figure 4). No relationship between Bcl-2 and OS was found, as the number of patients with $(\mathrm{H}) \mathrm{Bcl}-2$ was significantly lower than that of the other group (17 patients vs.66 patients).

OS was also analyzed in two patient groups. As the number of patients with (L) Bcl-2 was higher than the number of patients with $(\mathrm{H}) \mathrm{Bcl}-2$, these groups were analyzed according to Bax expression using the following equation: $(\mathrm{H}) \mathrm{Bax} /(\mathrm{L})$ $\mathrm{Bcl}-2(\mathrm{n}=39)$, and (L) Bax/(L) Bcl-2 ( $\mathrm{n}=26)$. In these groups, the median OS was determined to be 48.7 vs. 36.8 months for (H) Bax and (L) Bax, respectively $(\mathrm{p}=0.08)$

Early stage. The median OS was 64.4 months and 51.3 months, respectively for (L) Bax $(n=11)$ and $(H) B a x$ $(\mathrm{n}=27)$, which was not statistically significant $(\mathrm{p}=0.9)$. However, the $(\mathrm{H}) \mathrm{Bcl}-2(\mathrm{n}=13)$ group tended to have longer OS than the (L) Bcl-2 group ( $\mathrm{n}=25)$ (68.9 months vs. 39.6 months; $\mathrm{p}=0.06)$.

Advanced stage. Eighteen patients (40\%) had (L) Bax, whereas $27(60 \%)$ patients had $(\mathrm{H})$ Bax. The OS of the patients with $(\mathrm{H})$ Bax was longer than that for the patients with $(\mathrm{L}) \mathrm{Bax}$ (47.6 vs. 32.8 months; $\mathrm{p}=0.08$ ). $\mathrm{Bcl}-2$ was not associated with $\mathrm{OS}$ in the advanced stage, as a larger group of patients with advanced disease had low Bcl-2 (41/45). However, the OS of 
the patients in the (L) Bcl-2 / (L) Bax group was significantly shorter than the OS of (L) Bcl-2/ (H) Bax group (29.6 months vs. 48.7 months; $\mathrm{p}=0.05$ ) (Figure 5).

Disease-free survival and progression-free survival. The estimated median DFS was 45.9 months. DFS was longer in the $(\mathrm{H})$ Bax than in the (L) Bax group (47 months vs. 36.2 months; $\mathrm{p}=0.4)$. Similarly, the $(\mathrm{H}) \mathrm{Bcl}-2$ group had longer DFS than the (L) Bcl-2 group (45 months vs. 35.6 months; $\mathrm{p}=0.6$ ).

The median PFS in advanced disease was 16 months (minimum 14.9 months, maximum 17 months 95\% CI). The PFS of the patients with (L) Bax was 14.6 months, while it was 18.2 months for the $(\mathrm{H})$ Bax group ( $\mathrm{p}=0.28)$. No relationship was found between Bcl-2 and PFS (15.9 months for the (L) Bcl-2 group vs. 17.9 months for the $(\mathrm{H}) \mathrm{Bcl}-2$ group; $\mathrm{p}=0.88)$. Furthermore, the PFS comparison between the (L) Bax/(L) Bcl-2 group and the $(\mathrm{H}) \mathrm{Bax} /(\mathrm{L}) \mathrm{Bcl}-2$ group was not significant, but the $(\mathrm{H})$ Bax group tended to have longer PFS (14.6 months vs. 16.6 months; $\mathrm{p}=0.3$ ).

Table 3. Lymphocyte infiltrates and association with clinicopathologic and immunhistochemical findings

\begin{tabular}{|c|c|c|c|c|c|}
\hline \multirow{2}{*}{ Lymphocyte infiltrate } & \multicolumn{2}{|c|}{$<25$} & \multicolumn{2}{|c|}{$25-100$} & \multirow[t]{2}{*}{$P$ value } \\
\hline & $\mathbf{n}$ & $\%$ & $\mathbf{n}$ & $\%$ & \\
\hline \multicolumn{6}{|l|}{ Age } \\
\hline$\leq 50$ years & 19 & 55.8 & 15 & 44.2 & \\
\hline$>50$ years & 22 & 44.9 & 27 & 55.1 & 0.32 \\
\hline \multicolumn{6}{|l|}{ Histologic subtype } \\
\hline Serous & 22 & 44 & 28 & 56 & \\
\hline Endometrioid & 10 & 66.6 & 5 & 33.4 & \\
\hline Mixed & 2 & 25 & 6 & 75 & 0.28 \\
\hline Mucinous & 4 & 80 & 1 & 20 & \\
\hline Clear cell & 2 & 66.6 & 1 & 33.4 & \\
\hline Undifferantiated & 1 & 50 & 1 & 50 & \\
\hline \multicolumn{6}{|l|}{ Histologic grade } \\
\hline Well diff. & 12 & 92.3 & 1 & 7.7 & \\
\hline Moderately diff. & 13 & 40.6 & 19 & 59.4 & 0.003 \\
\hline Poorly diff. & 16 & 42.1 & 22 & 57.9 & \\
\hline \multicolumn{6}{|l|}{ FIGO stage } \\
\hline Early stage (I-II) & 20 & 52.6 & 18 & 47.4 & \\
\hline Advanced stage (III-IV) & 21 & 46.6 & 24 & 53.4 & 0.66 \\
\hline \multicolumn{6}{|l|}{ Residual Disease } \\
\hline$<1 \mathrm{~cm}$ & 21 & 48.8 & 22 & 51.2 & \\
\hline$>1 \mathrm{~cm}$ & 19 & 48.7 & 20 & 51.3 & 0.59 \\
\hline \multicolumn{6}{|l|}{ Platinum sensitivity } \\
\hline Platinium sensitive & 23 & 48.8 & 24 & 51.1 & \\
\hline Platinium resistant & 18 & 50 & 18 & 50 & 0.55 \\
\hline \multicolumn{6}{|l|}{ Bax expression } \\
\hline Low expression & 13 & 44.8 & 16 & 55.2 & \\
\hline High expression & 27 & 50 & 27 & 50 & 0.64 \\
\hline \multicolumn{6}{|l|}{ Bcl-2 expression } \\
\hline Low expression & 33 & 50 & 33 & 50 & \\
\hline High expression & 8 & 47 & 9 & 53 & 0.87 \\
\hline
\end{tabular}

Platinum sensitivity and its relation with protein expression. The platinum-sensitive group accounted of $56 \%(n=47)$ of patients, while platinum-resistant individuals accounted for $43.9 \%(n=36)$. The majority of the platinum-sensitive patients had early disease $(n=32,68 \%)$; conversely, the majority of platinum-resistant patients had advanced disease $(n=30,83 \%)$. Patients with $(\mathrm{H})$ Bax were significantly platinum-sensitive (72.3\% of the platinum-sensitive patients showed $(\mathrm{H}) \mathrm{Bax}$ protein expression; $\mathrm{p}=0.04)$. Similarly, the $(\mathrm{H}) \mathrm{Bax} /(\mathrm{L}) \mathrm{Bcl}-2$ group was more platinum-sensitive than the (L) Bax/(L) Bcl-2 group ( $61 \%$ vs. $38 \% \mathrm{p}=0.08)$.

Associations of TIL with clinicopathological features. The percentages of infiltrating lymphocytes for the patients are given in Table 3. No significant difference in the number of TIL was observed between the age groups; the patients under 50 years-old and over 50 years-old had almost the same degree of tumor lymphocyte infiltration $(\mathrm{p}=0.32)$. Similarly, mean age and mean serum postoperative CA125 level did not differ by the number of infiltrating lymphocytes $(p=0.43$ and $\mathrm{p}=0.53$, respectively). The number infiltrating lymphocytes in the tumor did not differ according to FIGO staging. The number of patients with L- and H-lymphocyte infiltration levels was almost the same in both early and advanced stages $(\mathrm{p}=0.66)$. The same results were seen when considered histological subtypes $(\mathrm{p}=0.77)$. Well-differentiated tumors had lower numbers of infiltrating lymphocytes (12 of 13 well-differentiated carcinomas had $<25$ infiltrating lymphocytes per nest), and as the tumor differentiation worsened, the amount of infiltrating lymphocytes increased $(p=0.003)$. The degree of lymphocyte infiltration did not differ between the platinum-sensitive and platinum-resistant groups; thus, there was no relationship between platinum sensitivity and tumor infiltrating lymphocytes.

Relationship between protein expression and TIL. The number of infiltrating lymphocytes was almost same in the Bax and $\mathrm{Bcl}-2$ high and low expression groups; however, when we evaluated this value for the Bax-Bcl2 couplet, the patients in the $(\mathrm{H}) \mathrm{Bax} /(\mathrm{L}) \mathrm{Bcl}-2$ expression group had lower number of infiltrating lymphocytes when compared with the patients in the (L) Bax/ (L) Bcl-2 group. Although the difference was not statistically significant $(\mathrm{p}=0.45)$, this finding may indicate that lymphocyte infiltration could be responsible for the Bcl-2-Bax ratio or vice versa.

TIL and survival analysis. The patients who had $<25$ lymphocytes per nest tended to have longer OS compared with those who had $\geq 25$ lymphocytes per nest (51.7 vs. 45.2 months). In the (L) Bax and L-lymphocyte infiltration group $(n=13)$, the OS was longer than that for the (L) Bax and H-lymphocyte infiltration group $(\mathrm{n}=16)$ (46 months vs. 36 months; $p=0.29$ ) (Figure 6). Similar results were observed in the Bax-Bcl-2 couplet. In the (L) Bax/(L)Bcl-2 group, patients with lower lymphocyte infiltration had longer OS than patients with higher lymphocyte infiltration (47.6 vs. 31.4 months; $\mathrm{p}=0.29$ ); however, lower lymphocyte infiltration did not confer a survival advantage in the $(\mathrm{H}) \mathrm{Bax} /(\mathrm{L}) \mathrm{Bcl}-2$ group. 
The summary of clinical and pathological parameters of entire study population is demonstrated in Table 4.

Cox regression analysis. Univariate analysis of clinical and pathological characteristics indicated that neither age $>50$, high tumor grade, lymphocyte infiltration greater than $\% 25$, or low expression of Bcl-2 protein was associated with an increased risk of progression (PFS) or death (OS). Both advanced stage and residual disease were associated with higher risk of progression and death. Higher Bax protein expression was significantly associated with lower risk of death ( $\mathrm{p}=0.04$; HR 0.47, 95\% CI 0.23-0.97) (Table 5). We then performed the Cox proportional multivariate analysis to investigate the strongest predictor and independent effect of each variable on survival. A model was set by using all of the predictors with $\mathrm{p}$ values lower than 0.1 in univariate analysis: Bax and Bcl-2 protein expression, stage, and operation procedure (suboptimal or optimal cytoreduction). Bcl-2 expression was added to the analysis due to the significant relationship between stage and $\mathrm{Bcl}-2$ expression despite a $\mathrm{p}$ value of 0.1 in the univariate analysis. Multivariate analysis revelaed that higher Bax protein expression was related with lower risk of death $(\mathrm{p}=0.03$; HR $0.4695 \%$ CI $0.22-0.95$ ) besides the strongest negative effect of advanced stage on both PFS and OS. Residual disease was also associated with higher risk of death in multivariate analysis (Table 6).

\section{Discussion}

The destruction of the regulation of the balance between proliferation and apoptosis is considered one of the most important features of malignant tumors [16]. However the association between clinicopathological features and Bcl2 and Bax expression remains unclear even after several clinical studies. There are conflicting reports regarding apoptotic-antiapoptotic protein expression and tumor histological subtype-grade $[13,16-20]$. In our study, the mucinous, clearcell and endometrial carcinomas tended to have higher Bax expression level, whereas the serous, mucinous, mixed and clear-cell subtypes had a tendency to have lower Bcl-2 expression level. As was shown in several previous studies, Bcl-2 and Bax expression was not associated with histologic type and grade in our study $[20,21]$.

Additionally, in selected studies, it was found that the presence of $\mathrm{Bcl}-2$ expression correlated with early stage tumors, whereas the presence of Bax expression was associated with advanced tumor stage [16,21]. Conversely, Mano et al. determined that $\mathrm{Bcl}-2$ expression was higher in patients with advanced tumor stage [22]. In the presented study, no significant correlation was found between tumor stage and Bax expression; however, Bcl-2 expression was significantly lower in advanced tumor stage as compared with early tumor stage.

Due to the antiapoptotic effect of the $\mathrm{Bcl}-2$ protein, it is expected that a worse clinical course will be observed in patients with high Bcl-2 expression level, and that a better prognosis

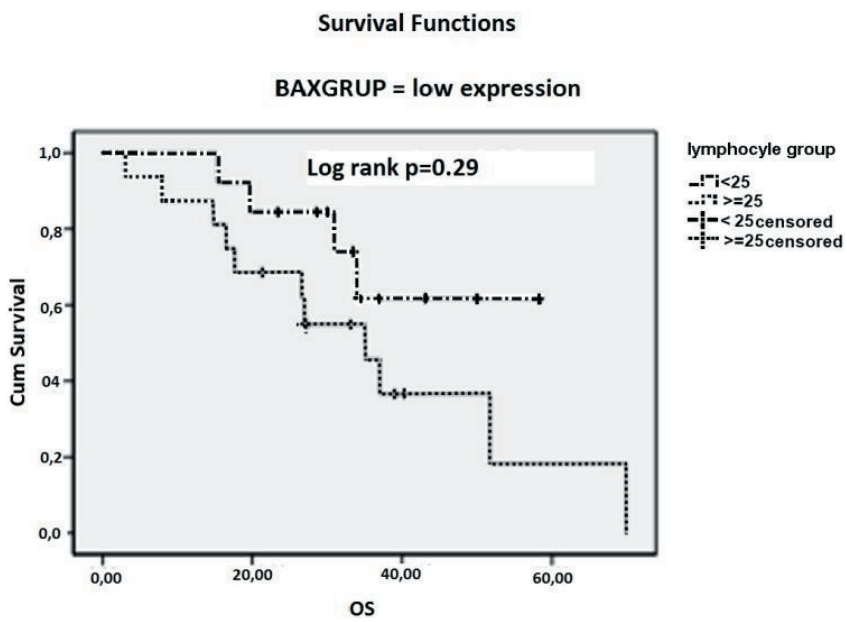

Figure 6. Overall survival comparison of the low Bax / low lymphocyte and low Bax /high lymphocyte infiltration groups.

Table 4. The summary of the clinical and pathological results of 83 patients.

\begin{tabular}{|c|c|c|}
\hline Patients characteristics & $\mathrm{n}$ & percent \\
\hline \multicolumn{3}{|l|}{ Age } \\
\hline$\leq 50$ & 34 & $41 \%$ \\
\hline$>50$ & 49 & $59 \%$ \\
\hline \multicolumn{3}{|l|}{ Histological type } \\
\hline Serous & 50 & $60.2 \%$ \\
\hline Non-serous & 33 & $39.8 \%$ \\
\hline \multicolumn{3}{|l|}{ FIGO stage } \\
\hline Early stage & 38 & $45.7 \%$ \\
\hline Advanced stage & 45 & $54.3 \%$ \\
\hline \multicolumn{3}{|l|}{ Bax expression } \\
\hline Negative & 25 & $30.1 \%$ \\
\hline Positive & 58 & $69.9 \%$ \\
\hline Low-score & 29 & $34.9 \%$ \\
\hline High-score & 54 & $65.1 \%$ \\
\hline \multicolumn{3}{|l|}{ Bcl-2 expression } \\
\hline Negative & 59 & $71.1 \%$ \\
\hline Positive & 24 & $28.9 \%$ \\
\hline Low-score & 66 & $79.5 \%$ \\
\hline High-score & 17 & $20.5 \%$ \\
\hline \multicolumn{3}{|l|}{ Lymphocyte infiltrate } \\
\hline$<25$ & 41 & $49.4 \%$ \\
\hline $25-50$ & 19 & $22.9 \%$ \\
\hline $50-75$ & 14 & $16.9 \%$ \\
\hline $75-100$ & 9 & $10.8 \%$ \\
\hline Median OS & Months & $95 \%$ confidence interval \\
\hline Whole group & 47.8 & $(40.3-57.1)$ \\
\hline Low Bax expression & 36.9 & $(23-50.9)$ \\
\hline High Bax expression & 49.8 & $(42.1-57.6)$ \\
\hline Low Bcl-2expression & 48.8 & $(39.3-52.1)$ \\
\hline High Bcl-2 expression & 59.2 & $(47.1-71.3)$ \\
\hline Low lymphocyte group & 51.7 & $(44.1-59.2)$ \\
\hline High lymphocyte group & 45.2 & $(37.4-52.9)$ \\
\hline
\end{tabular}


Table 5. Univariate analysis (Cox regression) for progression-free survival and overall survival in the 83 patients.

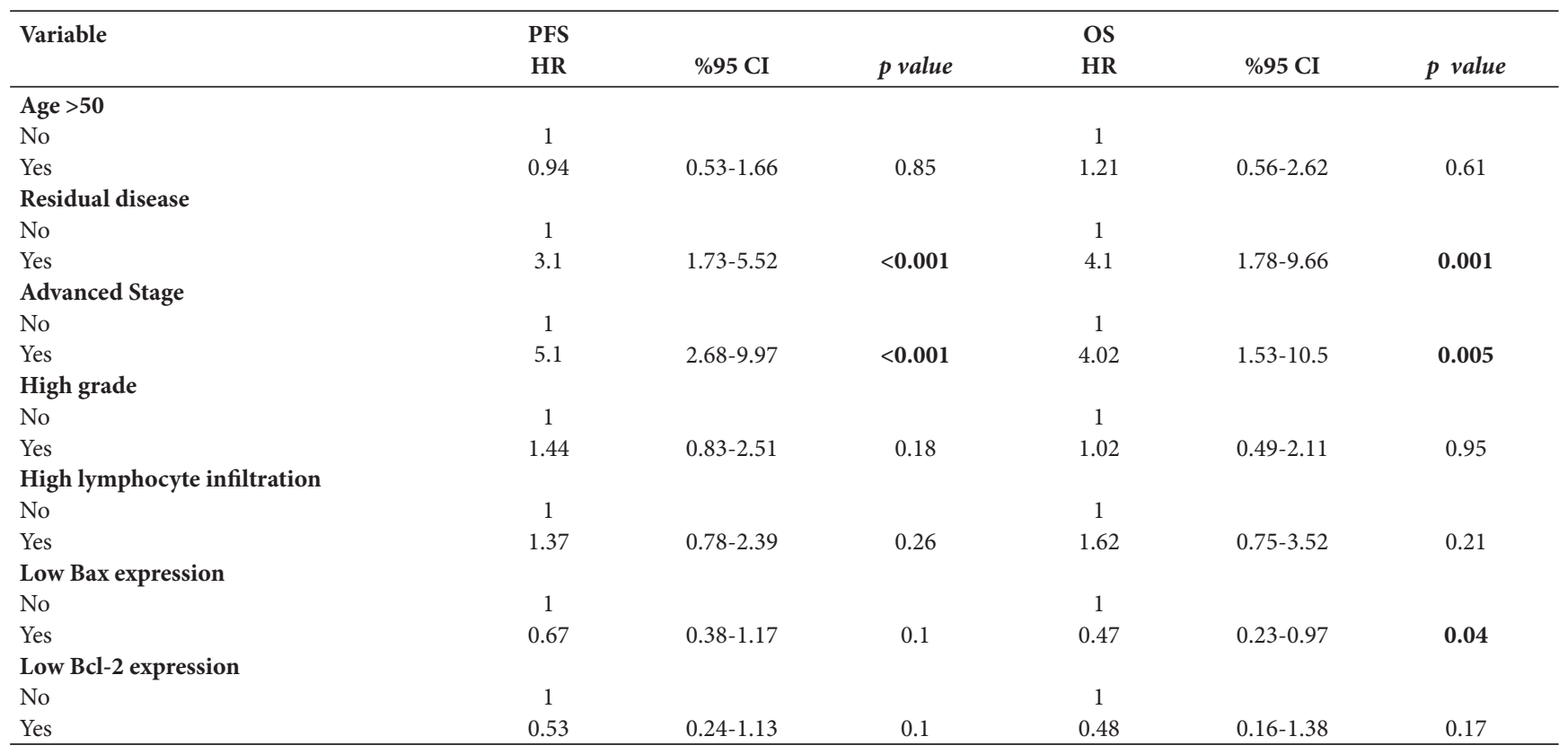

HR: Hazard ratio , PFS: Progression-free survival, OS: Overall survival

Table 6. Multivariate analysis (Cox regression) for progression-free survival and overall survival in the 83 patients.

\begin{tabular}{|c|c|c|c|c|c|c|}
\hline & PFS & & & OS & & \\
\hline Variable & HR & $95 \% \mathrm{CI}$ & p value & HR & $95 \% \mathrm{CI}$ & p value \\
\hline Advanced stage & 4.99 & $2.59-9.63$ & $<0.001$ & 1.93 & $0.6-6.18$ & 0.32 \\
\hline Residual Disease & 1.29 & $0.63-2.63$ & 0.4 & 4.13 & $1.75-9.70$ & 0.001 \\
\hline Bax expression & 0.63 & $0.35-1.12$ & 0.1 & 0.46 & $0.22-0.95$ & 0.03 \\
\hline Bcl-2 expression & 1 & $0.47-2.36$ & 0.88 & 1 & $0.29-3.40$ & 0.99 \\
\hline
\end{tabular}

HR: Hazard ratio, PFS: Progression-free survival, OS: Overall survival

will be observed in patients with lower Bcl-2 expression level. However, however the results of the previous studies regrading this hypothesis are conflicting. In several previous studies, $\mathrm{Bcl}$ 2 expression was correlated with good prognosis in ovarian cancer $[5,16,21,23]$. Conversely, Bcl-2 expression was correlated with poor prognosis in the study performed by Mano et al. [22]. In this study, no significant correlation between Bcl-2 expression and OS was found, similar to previous studies $[20,24]$. This may be due to the number of patients with high expression level (17/83) was significantly lower than the number of the patients with low expression level (66/83). The effect of the expression level of the Bax protein on survival was also unclear from the results of previous retrospective studies. Marx et al. demonstrated that the exclusive expression of Bax was significantly associated with reduced survival; however, Schuyer et al. demonstrated that high Bax expression level was associated with favorable survival $[16,21]$. In the presented study the OS of the $(\mathrm{H})$ Bax expression group was significantly longer when compared with the OS of the (L) Bax expression group 49.8 months and 36.9 months, respectively; $\mathrm{p}=0.03$ ).
The apoptosis-inhibiting effect of Bcl-2 has been shown to depend on its interaction with other family members, especially with the main antagonist, Bax [3]. The level of the $\mathrm{Bcl}-2$ and $\mathrm{Bax}$ proteins and the ratio of $\mathrm{Bcl}-2 / \mathrm{Bax}$ regulate the response of a cell to an apoptotic stimulus. When Bcl-2 is in excess, either Bcl-2- Bax heterodimers or Bcl-2 homodimers become predominant and protect the cells. When Bax is in excess, Bax homodimers predominate, the cell becomes susceptible to apoptosis [25]. In this study, we examined OS in 2 combinations of Bax and Bcl-2, namely; (L) Bax/ (L) Bcl-2 and, (H) Bax/ (L) Bcl-2. In the (L) Bax / (L) Bcl-2 expression group, the median OS was significantly shorter than the OS of the $(\mathrm{H}) \mathrm{Bax} /(\mathrm{L}) \mathrm{Bcl}-2$ group (29.6 months and 48.7 months; $\mathrm{p}=0.05)$. In a previous study, it was shown that the OS was shortened in patients with (-) Bax and (-) Bcl-2 expression compared with patients with (-) Bax and (+) Bcl-2 expression [16]. Schuyer et al.reported that the $(+)$ Bax-(+) Bcl-2 group had longer OS and PFS times than the (+) Bax-(-) Bcl-2 group (21). Due to the small number of (H) Bcl-2 patients, the $(\mathrm{H}) \mathrm{Bax} /(\mathrm{H}) \mathrm{Bcl}-2$ group could not 
be included in this study. We attribute the outcome that Bax expression has an effect on survival due to the longer OS seen in the patients with $(\mathrm{H})$ Bax expression.

The association between proapoptotic-antiapoptotic protein expression and taxane-platinum drug sensitivity had been evaluated in previous studies. An in vitro cancer cell line study suggested that the cell lines with high Bcl-2 levels had a predisposition towards sensitivity to platinum drugs [26]. There are various mechanisms underlying taxane resistance that have been previously described [27]. In several in vitro studies, it was demonstrated that excessive $\mathrm{Bcl}-2$ expression or impaired phosphorylation was responsible for taxane (docetaxel and paclitaxel) resistance; however, an opposite finding was reported by Ferlini et al., who suggested that Bcl-2 down regulation was responsible for paclitaxel resistance $[28,29,30]$. Additional conflicting results from several clinical studies have been reported. While Tai et al. reported higher rates of complete remission in patients with $(\mathrm{H}) \mathrm{Bax}$ expression, Geisler et al. observed the negative effect of Bcl2 protein expression on prognosis [24,31]. However, it was reported that high Bax expression had a negative effect on complete remission rates in a recent clinical study [32]. In our study, no relationship between platinum sensitivity and antiapoptotic Bcl-2 protein expression was demonstrated. Conversely, Bax expression was significantly higher in the platinum-sensitive group. Similarly, the (H) Bax / (L) Bcl-2 group were more sensitive to platinum than the (L) Bax/ (L) Bcl-2 group ( $\mathrm{p}=0.04)$.

Several studies have demonstrated that CD8 (+) TILs are predominantly associated with improved survival $[9,11,33]$. In a study that analyzed lymphocyte nests in benign, normal and malign ovarian lesions, it was demonstrated that TILs were associated with malign transformation. In our study, $<25$ lymphocytes per nest were found to be associated with well-differentiated tumors. Even though it was not confirmed statistically, the patients with $<25$ lymphocytes had a tendency of longer survival compared with the entire group. However, no relationship with platinum sensitivity was observed.

Limitations of presented study: Immunohistochemical staining analysis was performed manually. The number of patients, who had undergone optimal cytoreduction, was not sufficient for investigating the independent effect of these parameters in patients without residual disease. The number of patients with high $\mathrm{Bcl}-2$ protein expression was extremely lower than the number of patients with low Bcl-2 protein expression. Larger number of patient population in a uniform FIGO stage can be better for investigating the effect of Bcl-2 protein expression on survival times. The evaluation of lymphocyte subtypes (cytotoxic or $\mathrm{T}$ helper) can provide additional information.

\section{Conclusion}

This is the first study that evaluates the influence of TILs and proapoptotic-apoptotic proteins together with the clinico- pathological features of ovarian epithelial tumors on survival and in response to chemotherapy. This study demonstrates the following results:

1. Patients with $(\mathrm{H})$ Bax expression have significantly longer survival times than patients with (L) Bax expression.

2. Bcl-2 expression decreases with the tumor progression.

3. Tumor differentiation worsens as the lymphocyte number per nest increases.

4. There is no relationship between $\mathrm{Bax}$ or $\mathrm{Bcl}-2$ expression and the lymphocyte number.

5. Bax expression, but not $\mathrm{Bcl}-2$ expression, has a predictive value for platinum-based chemotherapy. Patients with higher level of Bax protein expression level are more sensitive to platinum-based chemotherapy.

6. TILs have no effect on the patient's response to chemotherapy.

Additional large and prospective studies are required to support the predictive role of Bax protein expression in treatment response. We have sufficient knowledge from previous studies, as mentioned above, that the lymphocyte subtype is important for survival. Although we did not evaluate the lymphocyte subtypes (CD8 -cytotoxic or CD4-T helper), we were able to demonstrate that the number of tumor infiltrating lymphocytes per nest increases with the tumor progression and that patients with lower number of tumorinfiltrating lymphocytes tend to have longer survival in all subgroups [(L)-(H) Bax, (L)-(H) Bcl-2, (L) Bax/(L) Bcl-2, (H) $\operatorname{Bax} /(\mathrm{L}) \mathrm{Bcl}-2]$.

Acknowledgements: This study was partly presented in 23rd European Congress of Pathology, Helsinki 2011. The authors would like to thank Miss Hulya Goren and Mr. Ayhan Kancar, Department of Pathology, Izmir Ataturk Research and Training Hospital, for their valuable technical support.

\section{References}

[1] JEMAL A, SIEGAL R, XU J, WARD E Cancer statistics 2010. CA Cancer J Clin 2010; 60: 277. http://dx.doi.org/10.3322/ caac. 20073

[2] TEWARI KS, KYSHTOOBAYEVA AS, METHA RS, YU IR, BURGER RA et al. Biomarker conservation in primary and metastatic epithelial ovarian cancer. Gynecol Oncol 2000; 78: 130-136. http://dx.doi.org/10.1006/gyno.2000.5837

[3] OLTVAI ZN, MILLIMANN CL, KORSMEYER SJ Bcl-2 heterodimerizes in vivo with a conversed homolog, Bax, that accelerates programmed cell death. Cell 1993; 74: 606-619

[4] BINDER C, MARX D, OVERHOFF R, BINDER L, SCHAUER A, HIDDEMANN W Bcl-2 protein expression in breast cancer in relation to established prognostic factors and other clinicopathologic variables. Ann. Oncol 1995; 6: 1005-1010.

[5] HEROD JJO, ELIPOULOS AG, WARWICK J, NIEDOBITEK $\mathrm{G}$, YOUNG LS et al. The prognostic significance of Bcl-2 and P53 expression in ovarian carcinoma. Cancer Research 1996; 56: $2178-2184$. 
[6] BINDER C, MARX D, BINDER L, SCHAUER A, HIDDEMANN W Expression of Bax in relation to Bcl-2 and other predictive markers in breast cancer. Ann Oncol 1996;7: 129-133. http://dx.doi.org/10.1093/oxfordjournals.annonc. $\underline{\mathrm{a} 010538}$

[7] PARMIANI G Tumor-infiltrating T cells-friend or foe of neoplastic cells? N Engl J Med 2005; 353: 2640-2641. http://dx.doi. org/10.1056/NEJMp058236

[8] ZHANG L, CONEJO-GARCIA JR, KATSAROS D, GIMOTTY PA, MASSOBRIO M et al. Intratumoral T cells, recurrence and survival in epithelial ovarian cancer. N Engl J Med 2003; 348: 203-213. http://dx.doi.org/10.1056/NEJMoa020177

[9] HAMANISHI J, MANDAI M, IWASAKI M, OKAZAKI T, TANAKA $Y$ et al. Programmed cell death 1 ligand 1 and tumor-infiltrating CD8+ T lymphocytes are prognostic factors of human ovarian cancer. Proc Natl Acad Sci 2007; 104: 3360-3365. http://dx.doi.org/10.1073/pnas.0611533104

[10] TOMSOVA M, MELICHAR B, SEDLAKOVA I, STEINER I Prognostic significance of CD3+ tumor-infiltrating lymphocytes in ovarian carcinoma. Gynecol Oncol 2008; 108: 415-420. http://dx.doi.org/10.1016/j.ygyno.2007.10.016

[11] CLARKE B, TINKER AV, LEE CH, SUBRAMANIAN S, VAN DE RIJN $M$ et al. Intraepithelial $T$ cells and prognosis in ovarian carcinoma: noval associations with stage, tumor type, and BRCA1 loss. Mod Pathol 2009;22: 393-402. http://dx.doi. org/10.1038/modpathol.2008.191

[12] LEFFERS N, FEHRMANN RS, GOODEN MJ, SCHULZE UR, TEN HOOR KA et al. Identification of genes and pathways associated with cytotoxic $\mathrm{T}$ lymphocyte infiltration of serous ovarian cancer. Br J Cancer 2010;103: 685-692. http:// dx.doi.org/10.1038/sj.bjc.6605820

[13] ANDERSON NS, TURNER L, LIVINGSTON S, CHEN R, NICOSIA SV, KRUK PA Bcl-2 expression is altered with ovarian tumor progression: an immunohistochemical evaluation. J Ovarian Res 2009; 2: 16. http://dx.doi.org/10.1186/1757-2215-2-16

[14] LEE KR, TAVASSOLI FA, PRAT J, DIETEL M, GERSELL DJ et al. Surface epithelial-stromal tumours. In: Tavassoli FA, Devilee P editors. World Health Organization Classification of Tumours. Pathology and Genetics. Tumours of the Breast and Female Genital Organs. Lyon: IARC Press, 2003: 117-145

[15] MILLER AB, HOOGSTRATEN B, STAQUET M, WINKLER A Reporting results of cancer treatment. Cancer 1981;47:207-214. http://dx.doi.org/10.1002/1097-0142(19810101)47:1<207:: AID-CNCR2820470134>3.0.CO;2-6

[16] MARX D, BINDER C, MEDEN H, LENTHE T, ZIEMEK T et al. Differential expression of apoptosis associated genes Bax and Bcl-2 in ovarian cancer. Anticancer Res 1997; 17: 2233-2240.

[17] SKIRNISDOTTIR I, SEIDAL T, GERDIN E, SORBES B The prognostic importance of $\mathrm{p} 53, \mathrm{Bcl}-2$, and Bax in early stage epithelial ovarian carcinoma treated with adjuvant chemotherapy. Int J Gynecol Cancer 2002; 12: 265-276. http://dx.doi. org/10.1046/j.1525-1438.2002.01121.x

[18] DE LA TORRE FJ, GARCIA A, GIL-MORENO A, PLANAGUMA J, REVENTOS J et al. Apoptosis in epithelial ovarian tumours: Prognostic significance of clinical and histopathologic factors and its association with the immunohistochemical expression of apoptotic regulatory proteins (p53, bcl-2 and bax). Eur J Obstet Gynecol Reprod Biol 2007;130: 121-128.

[19] CHAN WY, CHEUNG KK, SCHORGE JO, HUANG LW, WELCH WR et al. $\mathrm{Bcl}-2$ and $\mathrm{p} 53$ protein expression, apoptosis and p 53 mutation in human epithelial ovarian cancers. Am J Pathol 2000; 156: 409-417. http://dx.doi.org/10.1016/S00029440(10)64744-X

[20] MALAMOU-MITSI V, CRIKONI O, TIMOTHEADOU E, ARAVANTINOS G, VRETTOU E et al. Prognostic significance of HER-2, p 53, and Bcl-2 in patients with epithelial ovarian cancer. Anticancer Res 2007; 27: 1157-1166.

[21] SCHUYER M, VAN DER BURG MEL, HENZEN-LOGMANS SC, FIERET JH, KLIJN JGM et al. Reduced expression of BAX is associated with poor prognosis in patients with epithelial ovarian cancer: a multifactorial analysis of TP53, p21, BAX and BCL-2. British Journal of Cancer 2001; 85: 1359-1367. http://dx.doi.org/10.1054/bjoc.2001.2101

[22] MANO Y, KIKUCHI Y, YAMAMOTO K, KITA T, HIRATA $\mathrm{J}$ et al. Bcl-2 as a predictor of chemosensitivity and prognosis in primary epithelial ovarian cancer. Eur J Cancer 1999; 35: 1214-1219. http://dx.doi.org/10.1016/S0959-8049(99)00124$\underline{0}$

[23] BAEKELANDT M, KRISTENSEN GB, NESLAND JM, TROPE CG, HOLM R Clinical significance of apoptosisrelated factors $\mathrm{p} 53, \mathrm{Mdm} 2$, and $\mathrm{Bcl}-2$ in advanced ovarian cancer. J Clin Oncol 1999; 17: 2061-2068.

[24] GEISLER JP, GEISLER HE, MILLER GA, WIEMANN MC, ZHOU Z et al. P53 and Bcl-2 in epithelial ovarian carcinoma: Their value as prognostic indicators at a median follow up of 60 months. Gynecol Oncol 2000; 77: 278-282. http://dx.doi. org/10.1006/gyno.2000.5780

[25] BASU A, HALDAR S The relationship between Bcl2, Bax and P53: consequences for cell cycle progression and cell death. Mol Hum Reprod 1998; 4: 1099-1109. http://dx.doi. org/10.1093/molehr/4.12.1099

[26] BEALE PJ, ROGERS P, BOXALL F, SHARP SY, KELLAND LR $\mathrm{Bcl}-2$ family protein expression and platinum drug resistance in ovarian carcinoma. Br J Cancer 2000; 82: 436-40

[27] FERLINI C, RASPAGLIO G, MOZZETTI S, CICCHILLITTI L, FILIPPETTI $\mathrm{F}$ et al. The seco-taxane IDN5390 is able to target class III beta-tubulin and to overcome paclitaxel resistance. Cancer Res 2005; 65: 2397-2405. http://dx.doi. org/10.1158/0008-5472.CAN-04-3065

[28] CIARDIELLO F, CAPUTO R, BORRIELLO G, DEL BUFALO D, BIROCCIO A et al. ZD1839 (IRESSA), an EGFR-selective tyrosine kinase inhibitor, enhances taxane activity in bcl-2 overexpressing, multi-drug resistant MCF-7 ADR human breast cancer cells. Int J Cancer 2002; 98: 463-469. http:// dx.doi.org/10.1002/ijc.10230

[29] BOUNDY V, NAKANO S Src tyrosine kinase augments taxotere-induced apoptosis through enhanced expression and phosphorylation of Bcl-2. Br J Cancer 2002; 86: 463-469. http://dx.doi.org/10.1038/sj.bjc.6600080

[30] FERLINI C, RASPAGLIO G, MOZZETTI S, DISTEFANO $\mathrm{M}$, FILIPPETTI $\mathrm{F}$ et al. Bcl-2 down-regulation is a novel 
mechanism of paclitaxel resistance. Mol Pharmacol 2003;64: 51-58. http://dx.doi.org/10.1124/mol.64.1.51

[31] TAI YT, LEE S, NILOFF E, WEISMAN C, STROBEL T, CANNISTRA SA Bax protein expression and clinical outcome in epithelial ovarian cancer. J Clin Oncol 1998; 16: 2583-2590

[32] ZIOLKOWSKA-SETA I, MADRY R, KRASZEWSKA E, SZYMANSKA T, TIMOREK A et al. Tp53, Bcl-2 and Bax analysis in 199 ovarian cancer patients treated with taxane-platinum regimens. Gynecol Oncol 2009; 112: 179-84. http://dx.doi. org/10.1016/j.ygyno.2008.09.008

[33] LEFFERS N, GOODEN MJ, DE JONG RA, HOOGEBOOM BN, TEN HOOR KA et al. Prognostic significance of tumorinfiltrating T-lymphocytes in primary and metastatic lesions of advanced stage ovarian cancer. Cancer Immunol Immunother 2009; 58: 449-59. http://dx.doi.org/10.1007/s00262-008-0583$\underline{5}$ 